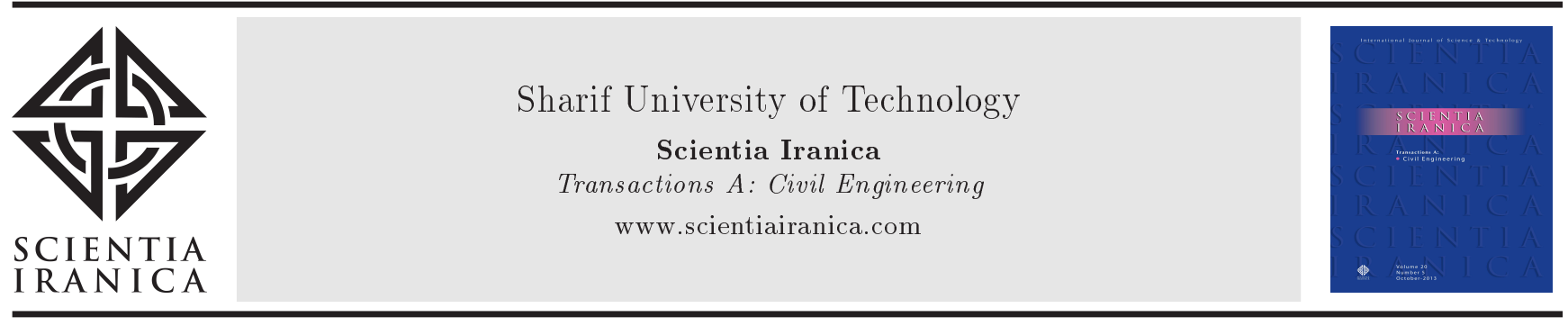

\title{
Experimental study on relation between scour and complex 3D flow field
}

\author{
M. Mehraein ${ }^{\mathrm{a}, \mathrm{b}, *}$ and M. Ghodsian ${ }^{\mathrm{c}}$ \\ a. Faculty of Engineering, Kharazmi University, Tehran, Iran. \\ b. Faculty of Civil and Environmental Engineering, Tarbiat Modares University, Tehran, Iran. \\ c. Water Engineering Research Institute, Faculty of Civil and Environmental Engineering, Tarbiat Modares University, Tehran, \\ Iran.
}

Received 9 September 2015; received in revised form 23 April 2016; accepted 31 December 2016

\section{KEYWORDS}

Experimental study;

Turbulent 3D flow;

Quadrant analysis;

Scour;

ADV.

\begin{abstract}
In this paper, scour and flow fields around two spur dikes with different submergence ratios located in a $90^{\circ}$ developed bend were experimentally investigated. The spur dike and scour rate around the low submerged spur dike are higher than those around the high submerged condition. The ejection and sweep events are the predominant events in the upstream region of the spur dike. The larger peak of the power spectrum and the higher frequencies of sweep and ejection events in the low-submerged condition increase the scour rate at the early stages of the scour process. Interaction events are the main events in the downstream recirculation zone and may be the principal reasons for the sediment deposition process. The scour initiation region cannot be predicted using variance of the vertical velocity component. However, the estimation of the bed shear stress using the Reynolds stresses can predict the scour initiation region correctly. Strong relationships between the scour rate and triple correlations, quadrant analysis, turbulent kinetic energy flux, and power spectrum were found because the scour rate increases in the low submergence condition by the latter parameters increments.
\end{abstract}

(C) 2017 Sharif University of Technology. All rights reserved.

\section{Introduction}

Spur dikes are training structures that may be used to protect river banks. Most of previous experiments on flow field around the spur dike were conducted to investigate the mean and turbulent parameters [110]. Chen and Ikeda [1] and Yossef [4] studied the flow pattern of emerged spur dikes and separated the flow fields into four main regions: main flow zone, return flow zone, shear layer, and reattachment point. Elawady et al. $[2,3]$ studied the qualitative nature of the flow field around a submerged spur dike. According to

*. Corresponding author. Tel.: +98218883089 E-mail address: mehraein@khu.ac.ir (M. Mehraein) this research, the fully submerged and just submerged spur dike flow fields are completely different, and the downstream recirculation region length depends on the spur dike's shape and height. Kuhnle et al. [11] measured the flow field around a submerged trapezoidal spur dike and numerically simulated the flow field. A good correlation between the numerical simulation and measured values was reported. Some researchers, such as Vaghefi et al. [8] and Ghodsian and Vaghefi [12], studied the mean flow field around a T-shaped spur dike in a $90^{\circ}$ bend and tried to find the relation between scour and mean flow features around the spur dikes. Safarzadeh et al. [13] showed that the maximum bed shear stress around a T-shaped spur dike is smaller than that around a straight spur dike. Hence, the scour hole around the straight spur dike is expected to be greater than the scour hole around a T-shaped 
spur dike. Azinfar (2010) [10] studied the flow field around emerged and submerged straight spur dikes, and showed that blockage ratio has prominent effect on the spur dike drag coefficient and associated backwater effect. Duan et al. [10] studied the turbulent parameters, the turbulence bursting process, and the sediment entrainment and deposition process around an emerged spur dike in the straight channel. They concluded that the scour occurred in the region where the sweep and ejection events had the main role in turbulent flow field. The relations between scour process and turbulent bursting process were studied by many researchers such as Grass [14], Nezu and Nakagawa [15], Nakagawa and Nezu [16], Nelson et al. [17], Keshavarzy and Ball [18], Keshavarzi and Gheisi [19], Bey et al. [20], Yaeger [21], Yager and Schmeeckle [22], Mehraein et al. [23,24], Mehraein et al. [25], Sarkar et al. [26], Soltani et al. [27], and Shrestha [28]. Nelson et al. [17] stated that the sweep event moves the sediment collectively, while the outward interactions move the sediments individually. According to Keshavarzy and Ball [18], Marchioli and Soldati [29], and Mianaei and Keshavarzy [30], bed load results from the sweep event, while suspended load results from the ejection event. According to the latter investigations, the deposition process occurred in the region where the interaction events were prevailing. They stated that the scour process was a three-dimensional process, and they presented a new method for quadrant analysis in 3D flow fields. Bey et al. [20] stated that the ejection and sweep events in near bed layers moved the sediments to the downstream as both suspended and bed loads. Recently, the relation between the scour process and three-dimensional flow field has been reported by Mehraein et al. [23,24], and the effect of the location of the emerged straight spur dike in the $90^{\circ}$ bend on scour and flow field has been clarified. They stated that the scour process mainly depended on near bed turbulent flow and the scour process related to the near bed turbulent flow field using the quadrant analysis.

To the best of the authors' knowledge, although the relation between the scour and flow field was studied extensively, it is necessary to investigate the relation between the scour process and the turbulence bursting events in detail for a complex 3D flow field such as spur dikes. In addition, the relation between scour and flow field around a submerged T-shaped spur dike in a $90^{\circ}$ bend is in its preliminary stages. As the spur dikes may be submerged during the flood, it is necessary to investigate the submergence effects on the flow field around a spur dike. Hence, the main objectives of this paper are as follows:

1. To investigate the relation between the scour process and the turbulent flow features in a complex 3D flow using turbulent flow parameters such as spectral analysis, power spectrum, contribution of the events in the Reynolds stresses, frequencies of the events, time fractional, triple correlation, and bed shear stress;

2. To investigate the mean and the turbulent flow parameters around a submerged T-shaped spur dike in a $90^{\circ}$ bend and clarify the submergence effects on the turbulent flow field.

\section{Experimental setup and procedure}

The experiments were conducted in a laboratory channel at Tarbiat Modares University, Tehran, Iran. The channel consists of three parts: straight upstream part $7.1 \mathrm{~m}$ long, straight downstream part $5.2 \mathrm{~m} \mathrm{long}$, and a $90^{\circ}$ bend that was located between these two parts. The width and depth of the channel were 0.6 and $0.7 \mathrm{~m}$, respectively. The channel was covered with uniform sediment. The median size and standard deviation of the sediment were $1.28 \mathrm{~mm}$ and 1.3 , respectively. A $90^{\circ}$ bend was used with central radius of $2.4 \mathrm{~m}$. According to Leschziner and Rodi [31], the bend was classified as the developed bend $(R / B=4)$. There was a tailgate at the end of the channel to regulate the water depth. A T-shaped spur dike with web and wing lengths of $9 \mathrm{~cm}$ was made of Plexiglas with thickness of $0.01 \mathrm{~m}$ and installed at section $45^{\circ}$ in the bend (Figure 1(a)). Discharge was measured by means of a calibrated flow

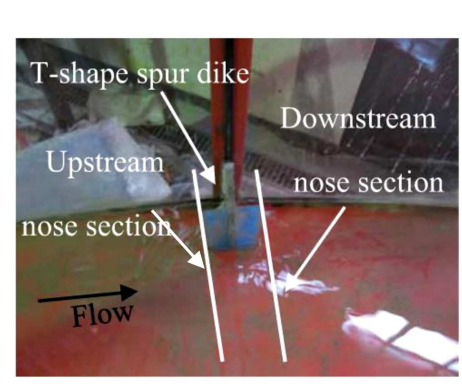

(a)

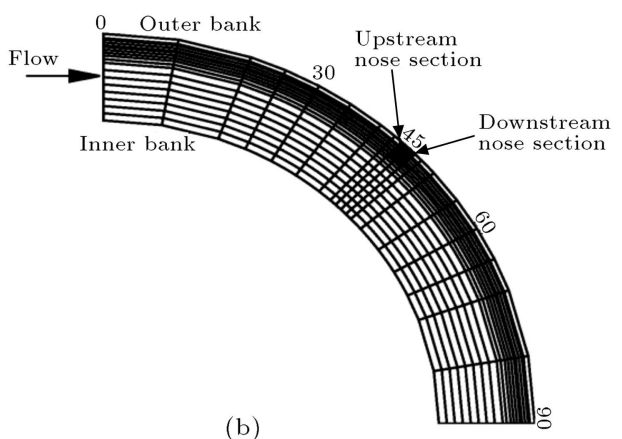

(b)

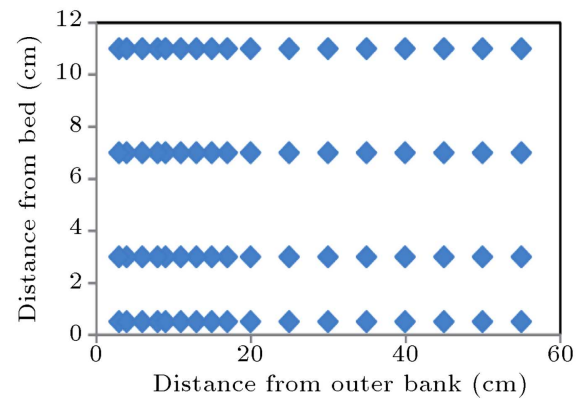

(c)

Figure 1. The instantaneous velocity's measuring points for $R / B=4$ : (a) Experimental setup, (b) plan, and (c) section view. 
Table 1. Experimental conditions.

\begin{tabular}{ccccccccc}
\hline $\boldsymbol{B}(\mathbf{c m})$ & $\boldsymbol{d}_{\mathbf{5 0}}(\mathbf{m m})$ & $\boldsymbol{l}(\mathbf{c m})$ & $\boldsymbol{L}(\mathbf{c m})$ & $\boldsymbol{h}(\mathbf{c m})$ & $\boldsymbol{\theta}\left({ }^{\circ}\right)$ & $\boldsymbol{Y}(\mathbf{c m})$ & $\boldsymbol{R}(\mathbf{c m})$ & $\boldsymbol{U}(\mathbf{c m} / \mathbf{s})$ \\
\hline 60 & 1.28 & 9 & 9 & 11.8 & 45 & $5.9,11.21$ & 2.4 & 35 \\
\hline
\end{tabular}

meter. Water depth was measured by a point gage with $\pm 0.1 \mathrm{~mm}$ accuracy.

The experiments were conducted in two stages of the low and high submergence ratios. In the first stage of the experiments, the flow field was measured for fixed bed condition. In this step, the bed surface was fixed using special resin so that no scour occurred during the experiments. Two experiments were done with the low-submergence ratio $(s=(h-Y) / h=5 \%)$ and the high-submergence ratio $(s=(h-Y) / h=50 \%)$, where $h$ is the water depth and $Y$ is the spur dike height from bed level. The instantaneous 3D-velocity components were measured by down-looking and the side-looking probes. The down-looking probe was used to measure the instantaneous velocity components at distances of $0.5-7 \mathrm{~cm}$ from the bed, and the sidelooking probe was used to measure the instantaneous velocity components at distances of $7-12 \mathrm{~cm}$ from the bed surface and near the spur dike. The sampling frequency of the measured instantaneous velocity was $50 \mathrm{HZ}$. The duration of velocity measurement was from 60 to 300 seconds as the time-independent mean velocity and the turbulent parameters were obtained. For an acceptable description of the turbulent flow parameters, the correlation coefficient and SNR (Signal Noise Ratio) should be greater than $70 \%$ and 14 , respectively [32]. The low-quality data were removed according to the above criteria, and the phase space threshold method was used to remove the spikes from the time series of the measured data [33]. The velocities were measured in cylindrical coordinates. The tangential, radial, and vertical axes were considered along the tangential, radial, and vertical directions of the bend. The origin of the vertical plane was at the sediment surface. The velocity components in tangential, radial, and vertical directions were denoted as $u, v$, and $w$, respectively. The plan view of the grids for the velocity measurement is shown in Figure 1(b). The 3D velocity components were measured at $0.5,3,7$, and $11 \mathrm{~cm}$ distances from the bed surface (Figure 1(c)). The flow visualization was also carried out by dye injection and colored ribbons.

In the second stage of the experiments, the sediment bed was not fixed, and the maximum scour depth was measured during the scour process to find the scour development rate. At first, the channel was filled with water from downstream, and then a discharge of $24.8 \mathrm{lit} / \mathrm{s}$ with the flow depth of $11.8 \mathrm{~cm}$ and the mean flow velocity of $35 \mathrm{~cm} / \mathrm{s}$ was generated using a pump installed in the upstream of the channel and the tailgate at the end of the channel. For the scour experiments, the temporal variation of maximum depth of the scour hole was recorded during 30 minutes after the scour initiation. Table 1 summarizes the details of the studied parameters. Scour and flow field experiments were conducted in similar conditions, except that the flow fields were measured in freeze bed condition.

In this table, $U$ is the mean approach flow velocity, $l$ is the spur dike wing length, $L$ is the spur dike web length, $d_{50}$ is the median sediment size, and $\theta$ is the location of the spur dike in the bend.

\section{Flow pattern and mean velocities}

Schematic views of the flow fields around the high and low submerged spur dikes are presented in Figure 2(a)(e). The secondary flow was formed because of the pressure gradient between the outer and inner banks caused by the centrifugal acceleration. The approach flow separated into two different parts in the vicinity of the spur dike web (Figure 2(a) and (b)). One part tended to the water surface (Figure 2(a)) and the other deviated towards the bed surface (Figure 2(b)). The downflow was stronger in the low-submerged condition, but in the high-submerged condition, the upflow was stronger. The downflow formed a reverse flow in the vicinity of sediment bed layer; the interaction between the reverse flow and the approaching flow formed a horse shoe vortex that was detected using dye injection in the near upstream nose region (Figure 2(b)). The flow patterns in the downstream region of the two spur dikes are different. As the upflow reached the crest of the spur dike, the falling flow was formed in the downstream region of the spur dike (Figure 2(a) and (c)). The falling flow touched the sediment bed surface in the high-submerged condition, but in the low-submerged condition, the falling flow slided at lower flow levels. In the high-submerged condition, the downstream recirculation flow was mainly formed due to the falling flow with the axis of the recirculation flow towards the banks (Figure 2(c)). However, the recirculation flow in the downstream of the low-submerged spur dike was mainly formed due to the passing of the main flow around the spur dike; the axis of this recirculation flow was roughly towards the sediment bed and water surface (Figure $2(\mathrm{~d})$ ). Vortex shedding process occurred from the upstream nose of the spur dikes (Figure 2(e)).

The time-averaged values of the tangential, radial, and vertical components of velocity (i.e., $u, v$, and $w$ ) in the upstream nose of spur dike are shown in Figures 3 


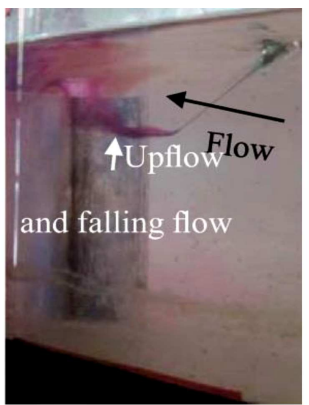

(a)

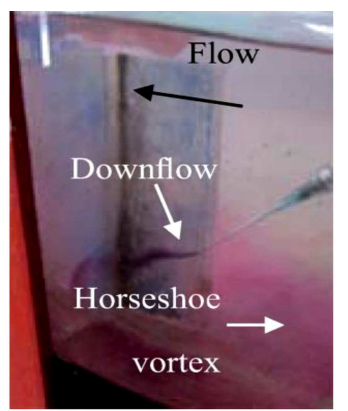

(b)

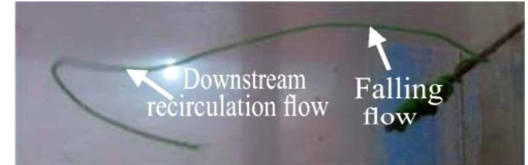

(c)

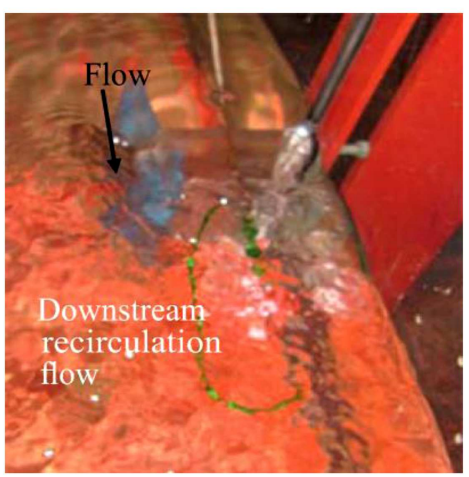

(d)

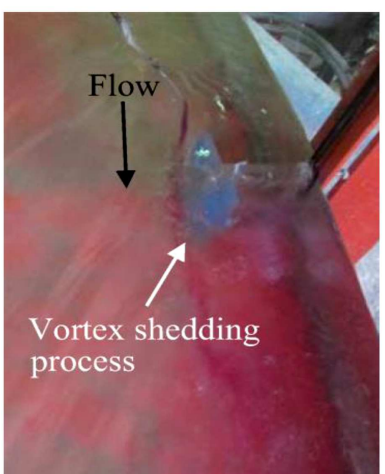

(e)

Figure 2. Schematic flow pattern around the spur dikes: (a) Upflow and falling flow in low-submerged condition, (b) downflow and horseshoe vortex, (c) vortex shedding process, (d) downstream recirculation flow in the low-submerged condition, and (e) falling flow and downstream recirculation flow in the high-submerged condition.

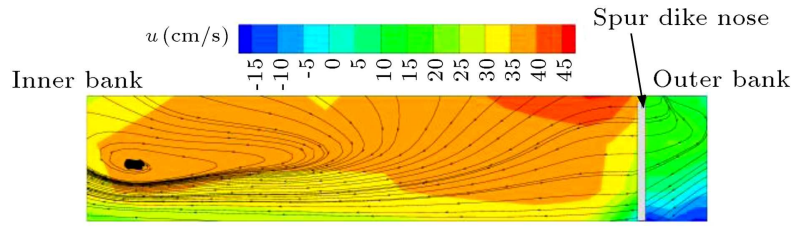

(a)

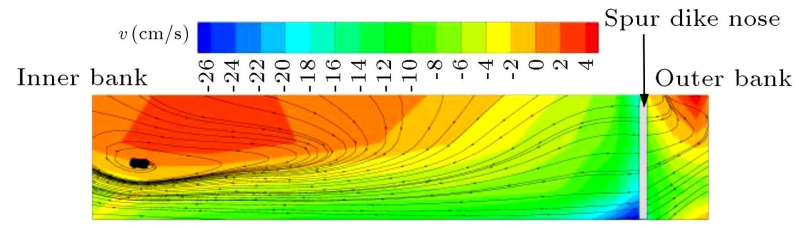

(b)

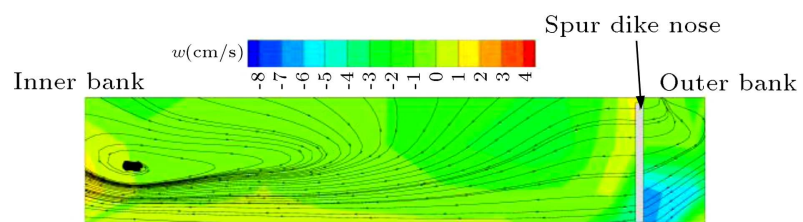

(c)

Figure 3. Distribution of velocity components in the upstream nose of the spur dike for the low-submergence ratio: (a) $u$, (b) $v$, and (c) $w$.

and 4. In the low-submergence ratio and near the bed surface (Figure 3(a) and (c)), negative values of $w$ indicate the downflow, while the negative values of $u$ indicate the reverse flow in the zone between the outer bank and the spur dike wing. Velocity measurements did not show the downflow and reverse flow in the upstream nose of the spur dike in the high-submergence ratio (Figure $4(\mathrm{a})$ and (c)). These flow types were detected using dye injection at the closer sections to the spur dike. It was found that the upstream reverse flow is more noticeable in the low-submergence ratio. The maximum values of the radial component of velocity $(v)$ occur near the upstream nose of the spur dike, and it is more highlighted in the low submergence ratio (Figure 3(b) and (b)).

Figures 5 and 6 show distribution of the velocity components at $\theta=45^{\circ}$ in the low and high submergence ratios. Comparison of values of $u$ in the low and high submergence ratios (Figure 5(a) and 6(a)) shows that the contraction of streamlines at the spur dike section in the low submergence ratio is higher because more flow passes around the spur dike. At $\theta=45^{\circ}$ and 


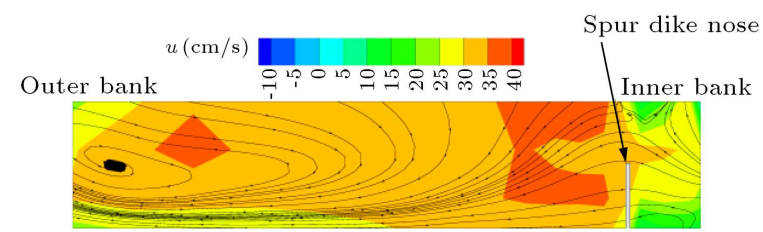

(a)

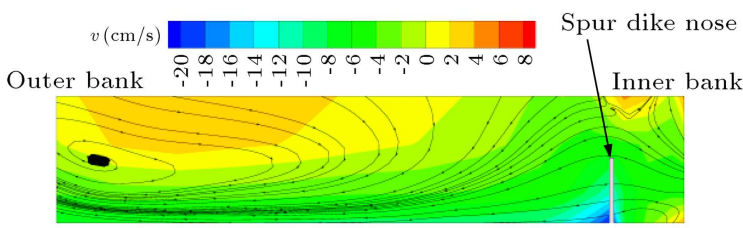

(b)

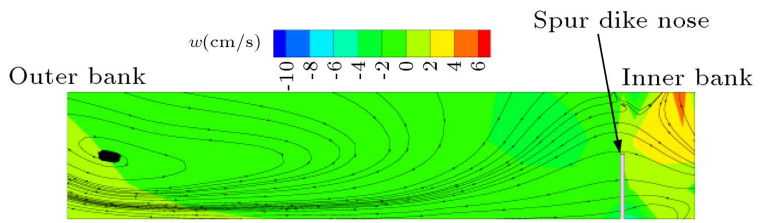

(c)

Figure 4. Distribution of velocity components in the upstream nose of the spur dike for the high submergence ratio: (a) $u$, (b) $v$, and (c) $w$.

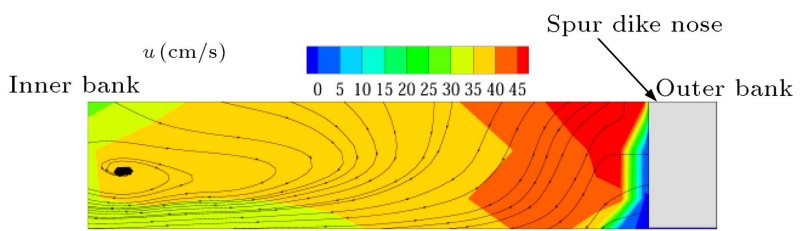

(a)

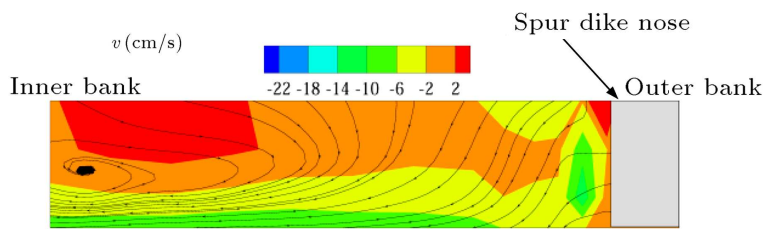

(b)

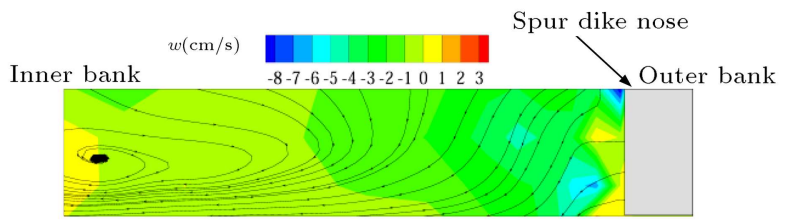

(c)

Figure 5. Distribution of velocity components at $\theta=45^{\circ}$ for the low-submergence ratio: (a) $u$, (b) $v$, and (c) $w$.

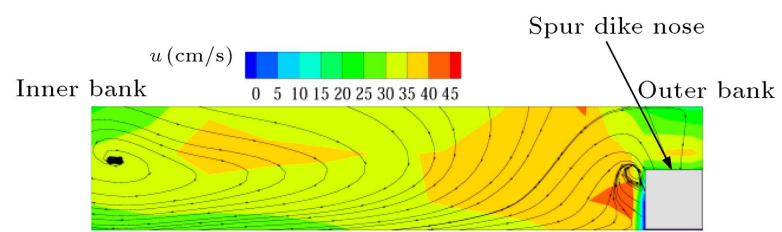

(a)

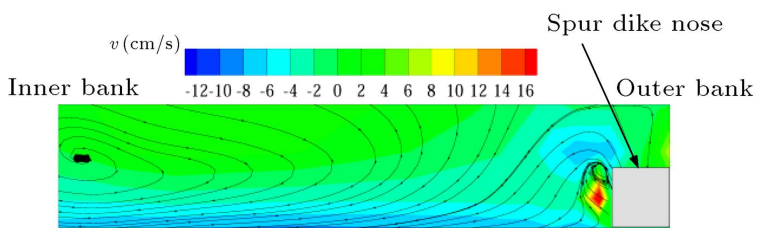

(b)

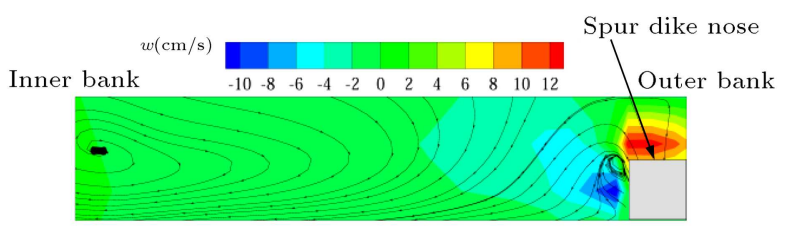

(c)

Figure 6. Distribution of velocity components at $\theta=45^{\circ}$ for the high-submergence ratio: (a) $u$, (b) $v$, and (c) $w$.

over the web of the spur dike, the vertical component of velocity, $w$, is greater in the high submergence ratio as compared to the low submergence ratio (Figures $5(\mathrm{c})$ and 6(c)). This also explains the stronger upflow in the high submergence ratio. In high submergence condition, the respective positive and negative values of $v$ and $w$ near the wing of the spur dike indicate a reverse flow formation towards the outer bank and sediment bed.

\section{Turbulent flow analysis}

\subsection{Spectral analysis}

Spectral analyses provide important time and spatial scales of the turbulent flow, in addition to detecting the inertial subrange. Spectral analysis can also be used to detect the frequencies that produce or dissipate the turbulent kinetic energy. The Fast Fourier Transform (FFT) of the auto-covariance function (Eq. (1)) of the 
velocity time measurement can be used to calculate the energy spectrum [34]:

$$
\begin{gathered}
\operatorname{Cov}_{j}(\Delta t)=\lim \frac{1}{2 T} \int_{-T}^{T}\left(V_{j}(t+\Delta t)-\bar{V}_{j}\right)\left(V_{j}(t)-\bar{V}_{j}\right) d t \\
\approx \frac{1}{N-K} \sum_{i=1}^{N-K}\left(V_{i j}-\bar{V}_{j}\right)\left(V_{i+K j}-\bar{V}_{j}\right) \\
i=1,2,3, \ldots, N, \quad j=x, y, z
\end{gathered}
$$

where $\Delta t$ is the time lag, $N$ is the total data number, and $K$ is the maximum lag or truncation time. The energy spectrum was calculated using the auto-covariance function as follows:

$$
s_{j}(f)=2 \int_{0}^{\infty} \operatorname{Cov}_{j}(\Delta t) \cos 2 \pi f \Delta t \quad d(\Delta t) .
$$

Here, $f$ is the frequency of velocity measurement. Figure $7(\mathrm{a})-(\mathrm{c})$ show the spectrum of the measured velocity for three different points located at $7 \mathrm{~cm}$ from bed in the center of the channel width for the low-submergence condition. The energy decreases by increasing the frequency as the energy is transferred from the lower frequency (large eddies) structures to the larger frequency (small eddies) structures. In the inertial subrange, the slope of the spectrum remains constant and it is equal to $-5 / 3$. In the upstream point, the inertial subrange can be found in $1<f<5$ $\mathrm{HZ}$, but in the downstream region, in the tight range of the frequency, the spectra obey the $-5 / 3$ slope. One of the most important differences between the upstream $\left(\theta=20^{\circ}\right)$ and downstream spectra $(\theta=$ $45^{\circ}$ ) is that in most of the frequency range of the downstream point, the energy decreases with higher slope compared to the upstream point spectrum. The upstream point spectrum has a larger value in the Nyquist frequency $\left(f_{N}=25 \mathrm{HZ}\right)$ for tangential and radial velocities.

The power spectrum analysis is useful in investigating the turbulent flow structure. The power of spectrum is an indicator of the three-dimensional velocity spectrums and can be calculated using Eq. (3):

$$
S(f)=\left\{S_{u}(f)^{2}+S_{v}(f)^{2}+S_{w}(f)^{2}\right\}
$$

Figure 8(a)-(c) show the power spectrum for two points in the region near the low and high submerged spur dikes. Parameter $r$ is the distance from the outer bank. The comparison between the power spectrum of the low and high submergence spur dikes shows that the peak value of the power spectrum in the low-submergence condition is greater than the peak value of the power spectrum in the high-submergence condition. Far from the wing of the spur dike, the peaks became smaller since the wing of the spur dike had minimal effects on the inner bank region.

Figure 9(a)-(c) show the power spectrum in different points along the channel for the low-submerged spur dike. All points are at a distance of $7 \mathrm{~cm}$ from bed surface. The maximum value of the power spectrum in the upstream region of the spur dike occurs in about $0.2 \mathrm{HZ}$ and the maximum value is equal to $60\left(\mathrm{~cm}^{2} / \mathrm{s}\right)^{2}$. In the shear layer region (Figure $9(\mathrm{~b})$ ), in the vicinity of spur dike, the peak value of the power spectrum,

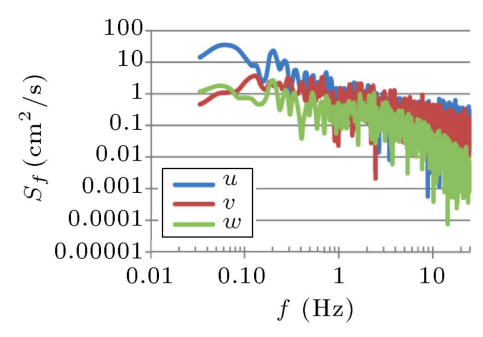

(a)

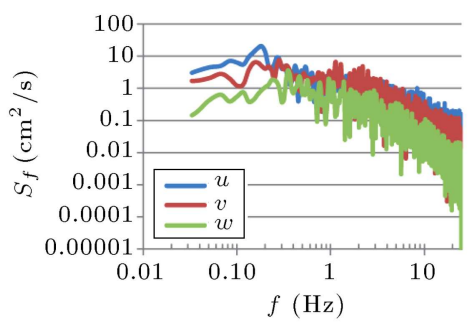

(b)

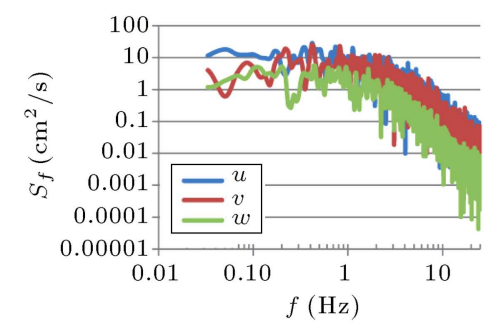

(c)

Figure 7. Velocity spectra for $(r, \theta, z)=(30 \mathrm{~cm}, \theta, 7 \mathrm{~cm}):$ (a) $\theta=20^{\circ}$, (b) $\theta=45^{\circ}$, and (c) $\theta=90^{\circ}$.

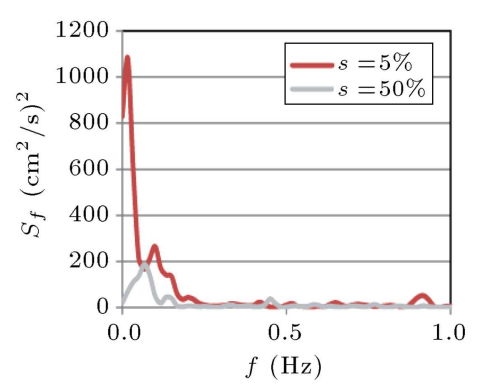

(a)

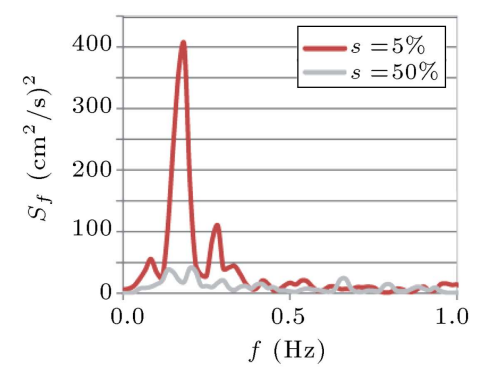

(b)

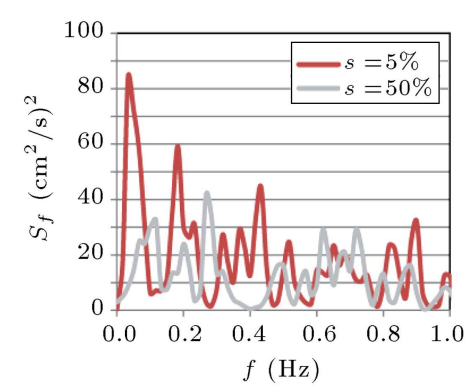

(c)

Figure 8. Power spectrum for $z=7 \mathrm{~cm}$ and $\theta=45^{\circ}$ : (a) $r=15 \mathrm{~cm}$, (b) $r=30 \mathrm{~cm}$, and (c) $r=55 \mathrm{~cm}$. 


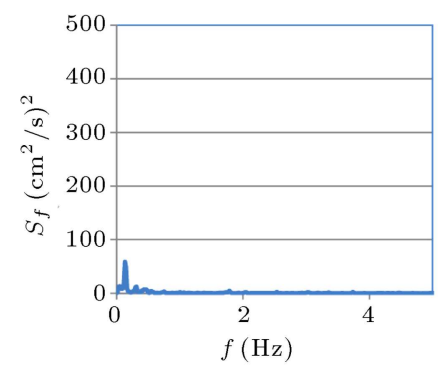

(a)

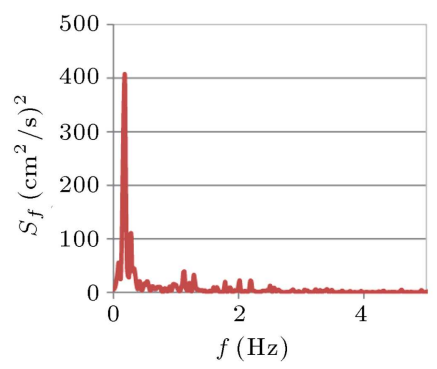

(b)

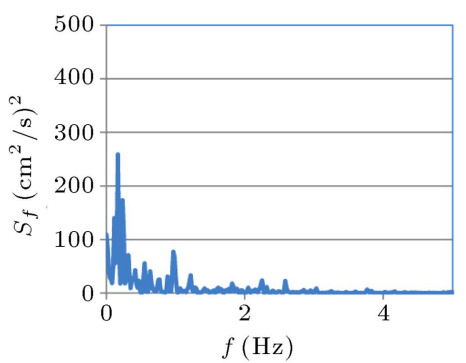

(c)

Figure 9. Power spectrum for $z=10 \mathrm{~cm}, r=30 \mathrm{~cm}$, and $s=5 \%$ in low submergence condition: (a) $\theta=20^{\circ}$, (b) $\theta=45^{\circ}$ and (c) $\theta=46.25^{\circ}$.

formed in the region between the spur dike and the main flow, increases significantly due to the vortex shedding process and decreases further from the spur dike location. The peak values of the power spectrum are an indicator of the power of the vortices, and the power of the vortices can be related to the sediment movement capacity of the vortices. It is expected to observe the sediment capacity transport of the vortices decrease in the downstream region by decreasing the power spectrum peak.

\subsection{Contributions of the turbulence bursting events}

The turbulence bursting events are the results of the wavy layer formation in the near bed flow region [35]. The sweep and ejection are positive in Reynolds shear stresses, but the interaction events (inward and outward interactions) have negative signs in Reynolds shear stress. The analysis of the turbulence bursting events provides valuable information in sediment transport studies. Quadrant analysis is one of the common procedures for analyzing the turbulence bursting process [36]. In the quadrant analysis, the velocity fluctuation space was divided into 5 different regions [15]. Region 1 is the outward interaction event $\left(u^{\prime} i>0\right.$ and $\left.w^{\prime}>0\right)$, region 2 is the ejection event $\left(u^{\prime} i<0\right.$ and $\left.w^{\prime}>0\right)$, region 3 is the inward interaction event $\left(u^{\prime} i<0\right.$ and $\left.w^{\prime}<0\right)$, and region 4 is the sweep event $\left(u^{\prime} i>0\right.$ and $\left.w^{\prime}<0\right)$. Here, $u^{\prime} i$ is the surface component velocity fluctuation $\left(u^{\prime}, v^{\prime}\right)$, and $w^{\prime}$ is the depth velocity fluctuation component. Region 5 is a hole region where $\left|u_{i}^{\prime} w^{\prime}\right|<H u_{r m s}^{\prime} w_{r m s}^{\prime}$. Here, $H$ is the hole size [20]. The points in the hole region have minimal effect on flow turbulence. Based on the hole size, each event (sweep, ejection, inward interaction, and outward interaction) can be defined quantitatively using the contribution rate of the events in Reynolds stresses $\left(R_{S}(H)\right)$ and the time fraction $\left(T_{s}(H)\right)$ of the events using Eqs. (4)(8) $[15]$ :

$$
R_{s}(H)=\int_{H}^{\infty} \phi \rho_{q}(\phi) d \phi, \quad Q_{2}, Q_{4}
$$

$$
\begin{aligned}
& R_{s}(H)=\int_{-\infty}^{-H} \varphi \rho_{q}(\varphi) d \varphi, \quad Q_{1}, Q_{3}, \\
& T_{s}(H)=\int_{H}^{\infty} \rho_{q}(\phi) d \phi, \quad Q_{2}, Q_{4}, \\
& T_{s}(H)=\int_{-\infty}^{-H} \rho_{q}(\phi) d \phi, \quad Q_{1}, Q_{3}, \\
& \phi=\frac{u_{i}^{\prime} w^{\prime}}{\left|u_{i}^{\prime} w^{\prime}\right|} .
\end{aligned}
$$

Here, $\rho_{q}(\phi)=2 \rho_{g}(\varphi)$ is the probability density function, $\rho_{g}(\varphi)=\frac{R}{2 \pi} \exp (R x) \frac{K_{0}(|x|)}{\left(1-R^{2}\right)^{0.5}}, x=\frac{R \varphi}{1-R^{2}}$, $K_{0}(|x|)$ is the 0th order modified Bessel function of the second kind, $R$ is the correlation coefficient of the Reynolds stress, $\varphi$ is the non-dimensional form of the instantaneous Reynolds stress, and $Q_{i}$ is the $i$ th region of the quadrant analysis.

Figure 10 shows the contribution rate and fractional time variation of the events with the hole size $(H)$ in the upstream of the spur dike. The contribution rate and fractional time of the ejection and sweep events are more than those of the interaction events for all $H$ values since the shear stress is positive in the upstream of the spur dike region and the flow can transport the sediment to the downstream.

Many investigators, such as Bey et al. [20], used constant $H$ (for example $H=2$ ) in the contribution of event analysis. In this stage, it was supposed that $H=$ 2. However, results did not change with a variation in $H$ values. As the near bed layer flow has strong effect on sediment transport process, the analyses were conducted for this region.

Figure 11(a) and (b) show the variation of the contribution rate of the events at $\theta=45^{\circ}$ in the near bed layer $(z=0.5 \mathrm{~cm})$ for low and high submergence conditions. In $u^{\prime} w^{\prime}$ analyses, ejection event has the most contribution in Reynolds stress, which is more pronounced in the low-submergence condition. The sweep and ejection events' contributions are almost equal near the inner bank, but ejection event has the main role in Reynolds stress near the spur dike wing 


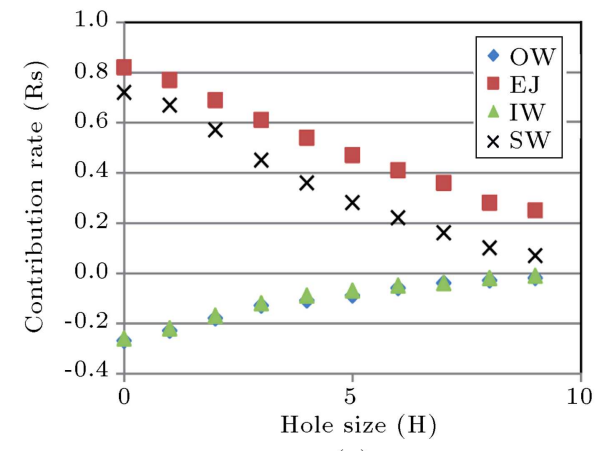

(a)

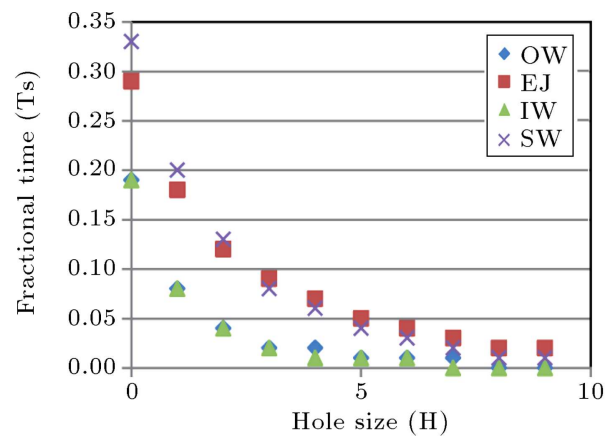

(b)

Figure 10. Contribution variation of the four events with hole size for $r=30 \mathrm{~cm}, z=0.5 \mathrm{~cm}, \theta=20^{\circ}$ : (a) Contribution rate of the events in Reynolds stresses, and (b) fractional time.

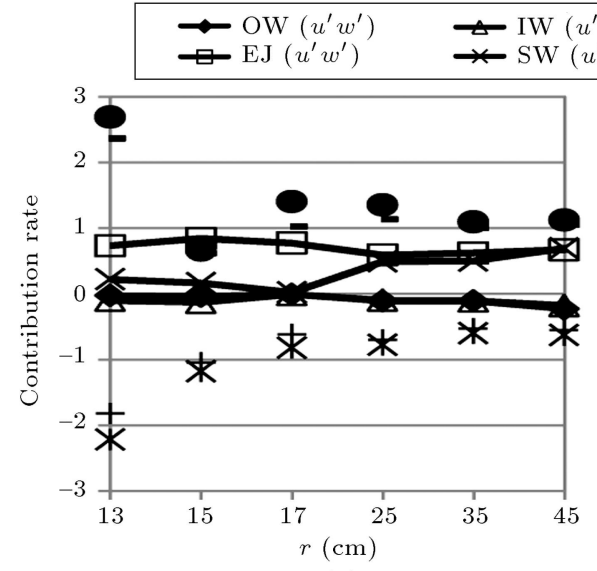

(a)

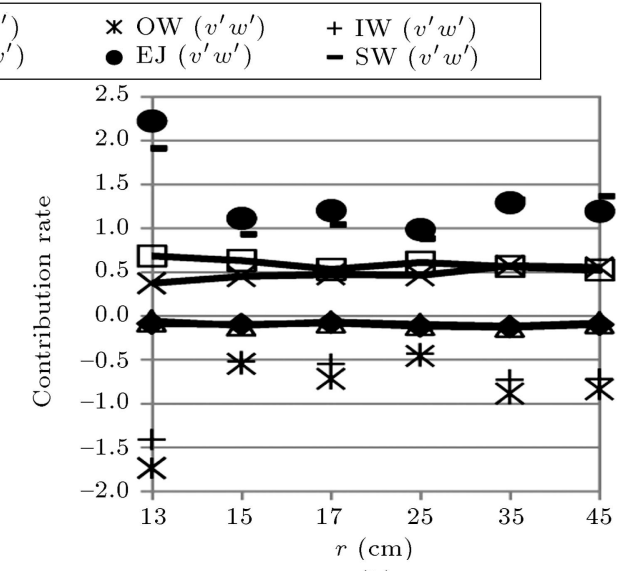

(b)

Figure 11. Contribution rate variation with $r$ at $\theta=45^{\circ}$ and $z=0.5 \mathrm{~cm}$ : (a) $s=5 \%$ and (b) $s=50 \%$.

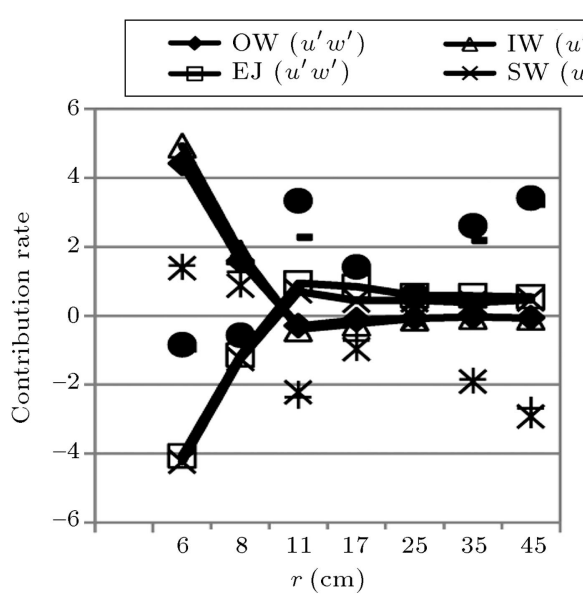

(a)

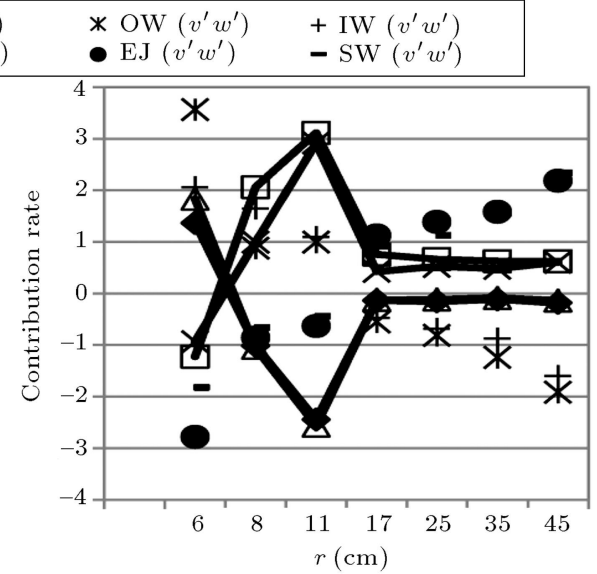

(b)

Figure 12. Contribution rate variation with $r$ at $\theta=50^{\circ}$ and $z=0.5 \mathrm{~cm}$ : (a) $s=5 \%$ and (b) $s=50 \%$.

and in shear layer region $(13<r<20 \mathrm{~cm})$. In the high-submergence condition, the contribution rates of the interaction events are almost equal at different distances from the banks, but those of the interaction events in the low-submergence condition increase near the inner bank region. In $v^{\prime} w^{\prime}$ analysis, the sweep and ejection events have the main contributions in shear
Reynolds stress of radial direction, and they are more substantial in the near spur dike wing. In the near spur dike wing, the contributions of the sweep and ejection events are larger for the low submergence spur dike.

The contribution rates of different events for $\theta=50^{\circ}$ are presented in Figure $12(\mathrm{a})$ and (b). A complex nature of the contribution rates can be 
observed in this section. In the recirculation zone, $u^{\prime} w^{\prime}$ contribution analysis shows that the contribution rates of the interaction events are significant. However, the sweep and ejection events have more contribution rates as one moves away from this region. For $v^{\prime} w^{\prime}$ analysis, the same trend can be observed for the lowsubmergence condition, but in the high-submergence condition, the contribution rate of the interaction events also is predominant in shear layer.

Figure 13 shows the contribution rate of the four events in the radial direction $\left(v^{\prime} w^{\prime}\right)$ for the near water surface level $(z=11 \mathrm{~cm})$. The interaction events are dominant in all points except near the outer bank region where the sweep and ejection events are the predominant events. This confirms the small secondary flow formation in the near water surface of the outer bank due to the stagnation point formation. The small

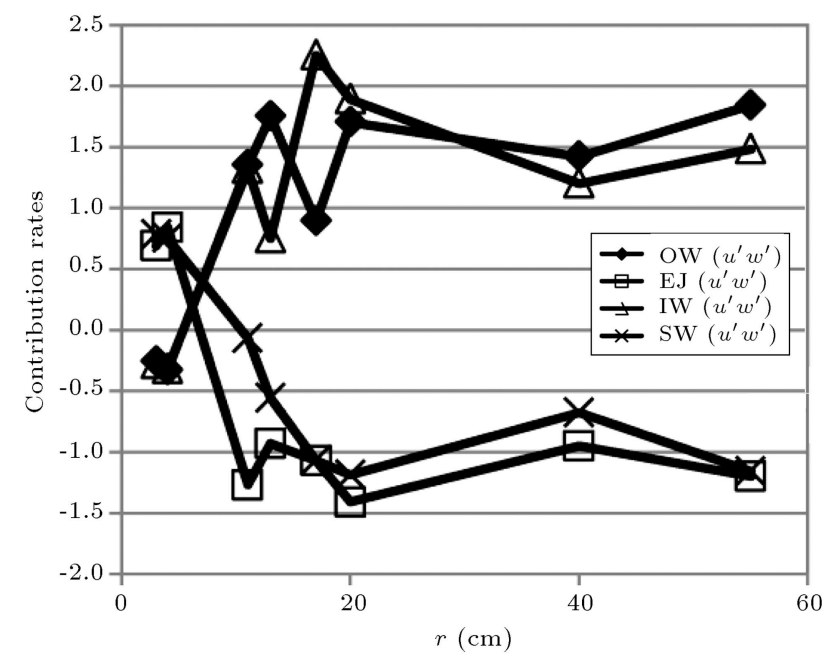

Figure 13. Contribution rates of the events in near water surface level for $\theta=30^{\circ}$.

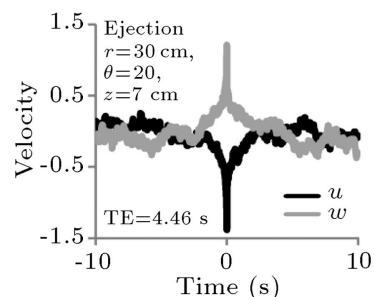

(a)

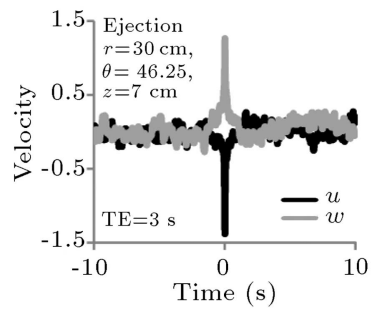

(e)

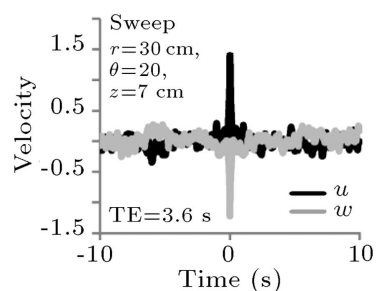

(b)

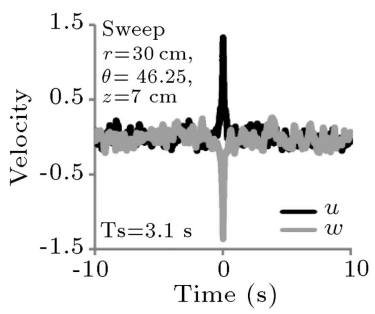

(f)

secondary flow may increase the flow scour potential in the outer bank of the channel.

To evaluate the periods of the events, the conditional average procedure can be used. The conditional average procedure for arbitrary signals can be defined using Eqs. (9) and (10) [15]:

$$
\begin{aligned}
\langle q(t)\rangle & =\frac{\int_{0}^{T} q(t+\Delta t) I_{i}(t) d t}{\int_{0}^{T} I_{i}(t) d t}, \\
I_{i}(t) & = \begin{cases}1, & u_{j}^{\prime}, w^{\prime} \text { in } Q_{i} \text { and } u_{j}^{\prime} w^{\prime}>H \overline{u_{j}^{\prime} w^{\prime}} \\
0, & \text { otherwise }\end{cases}
\end{aligned}
$$

where $I_{i}(t)$ is the detection function for the events. Figure 14(a)-(h) show the conditional average velocity of the predominant events of different points. TE is the period of the ejection events, TS is the period of the sweep events, TI is the period of the inward interaction event, and TO is the period of the outward interaction event. The periods of the events were considered as the time durations in which the signs of the surface and depth of conditional velocity components changed in the two sides of the ordinate. In the upstream region of the spur dike, the period of the ejection event is slightly greater than that of sweep events. This trend can also be seen in the shear layer region, but the periods of the ejection and sweep events are shorter in this region as compared to the upstream region of the spur dike. In the downstream region of the spur dike, the periods of the ejection and sweep events increase compared to the upstream region. Hence, the minimum periods of the sweep and ejection events are expected to occur near the spur dike location. The interaction events' periods are shorter in the recirculation zone of the spur dikes, which confirm the high repetition process of the events.

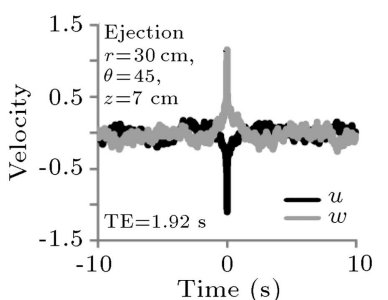

(c)

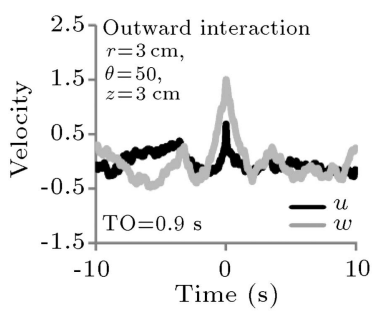

(g)

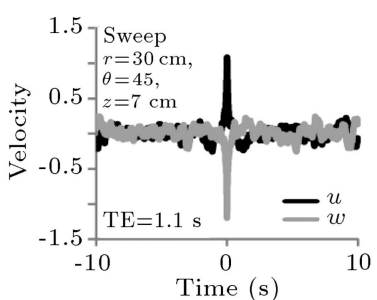

(d)

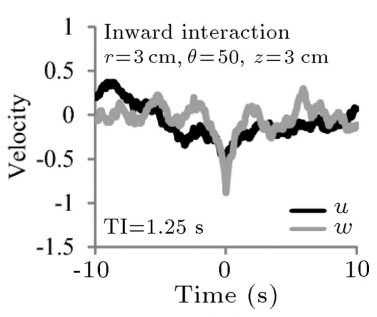

(h)

Figure 14. Conditional average velocity of the predominant events of different points for low-submergence condition: (a, b) Upstream location of the spur dike, (c, d) spur dike location section, and (e, f, g, and h) downstream recirculation region. 


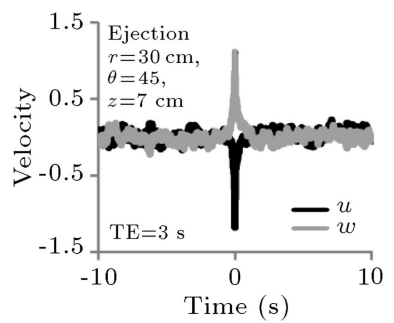

(a)

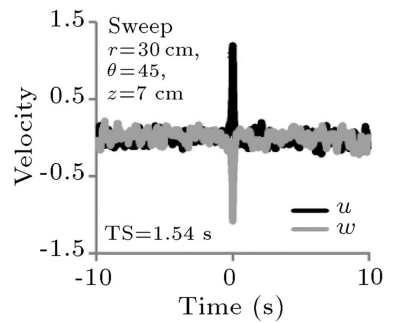

(b)

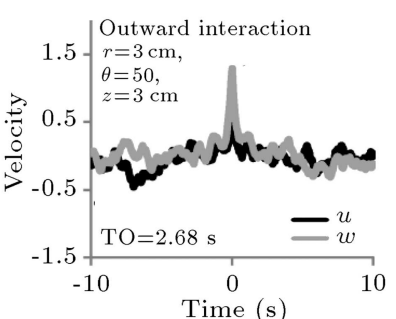

(c)

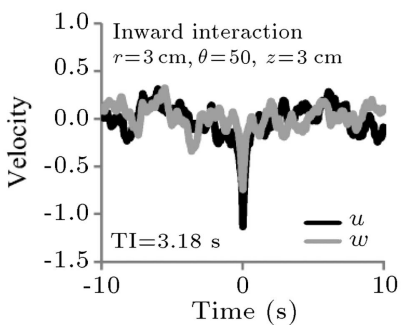

(d)

Figure 15. Conditional average velocity of the predominant events of different points for the high-submergence condition: $(\mathrm{a}, \mathrm{b})$ Spur dike location section, and $(\mathrm{c}, \mathrm{d})$ downstream recirculation region.

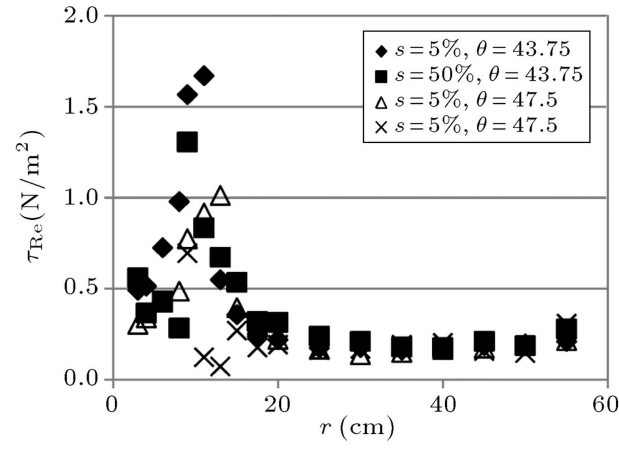

(a)

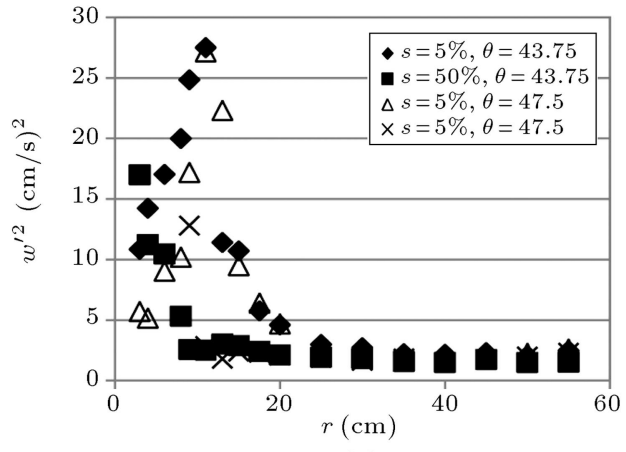

(b)

Figure 16. Variation of the turbulent parameters in the radial direction: (a) Estimation of the bed shear stress using Reynolds shear stresses, and (b) variance of the vertical velocity component.

Figure 15(a)-(d) show the sweep and ejection periods near the spur dike and interaction events in the downstream recirculation zone in high submergence condition. Comparisons between the periods of the events in low and high submergence spur dikes confirm that the sweep and ejection periods in the near spur dike region and the interaction periods in the recirculation zone in the high-submergence condition are greater than those in the case of the low-submergence spur dike.

One of the most common parameters probably used in sediment transport process is the bed shear stress. Bed shear stress can be estimated using the Reynolds stresses, turbulent kinetic energy, and the depth velocity fluctuation [37]. Since Acoustic Doppler Velocimeter (ADV) noise in the vertical direction is less than the noise of the surface velocity components, Kim et al. (2000) [38] suggested a linear relationship between bed shear stress and vertical velocity component variance. In this paper, the single-point approach is used to estimate the bed shear stress. According to this approach, the bed shear stress can be calculated using time series of the velocities in the near bed layer using Eqs. (11)-(14) [38,39]:

$$
\begin{gathered}
\tau_{\theta}=a b s\left(-\rho\left(\overline{u^{\prime} w^{\prime}}+\overline{u^{\prime} v^{\prime}}\right)\right), \\
\tau_{r}=a b s\left(-\rho\left(\overline{v^{\prime} w^{\prime}}+\overline{u^{\prime} v^{\prime}}\right)\right),
\end{gathered}
$$

$$
\begin{aligned}
& \tau_{R e}=\sqrt{\left(\tau_{r}\right)^{2}+\left(\tau_{\theta}\right)^{2}}, \\
& \tau_{w^{\prime}}=C \rho w^{\prime 2}
\end{aligned}
$$

Here, $u^{\prime}, v^{\prime}$, and $w^{\prime}$ are the velocity fluctuations in tangential, radial, and vertical directions, respectively; $\tau_{R e}$ is the estimation of the bed shear stress using Reynolds stress; $\tau_{w^{\prime}}$ is the bed shear stress estimation using vertical velocity fluctuation; $c$ is the constant equal to 0.9 for ocean flows and it has not been calibrated for river flows [38]. Figure 16(a) and (b) show the variation of bed shear stress, $\tau_{R e}$, and the variance of the vertical component of the velocity in different sections of near bed layer $(z=0.5 \mathrm{~cm})$. In the upstream nose section of the spur dikes, the maximum bed shear stress occurred near the nose region, and the bed shear stress in the low-submergence condition is greater than that in the high-submergence condition. The submergence affects the bed shear stress for $r<$ $20 \mathrm{~cm}$, and the bed shear stresses for high and low submergence conditions are practically the same for $r>20 \mathrm{~cm}$. In the downstream nose section of the spur dike, the bed shear stress estimation has the maximum value at the shear layer. The bed shear stresses at the outer region of the recirculation region are almost equal for low and high submergence conditions. The maximum value of the bed shear stress at the shear layer in the low-submergence condition is greater than that in the high-submergence condition. The vertical 
velocity component variance shows similar trends to the estimation of the bed shear stress using Reynolds shear stress, except that the vertical velocity intensity in the upstream nose section decreases with a distance from the outer bank.

The third-order moments are the weighted mean of the instantaneous Reynolds stresses. The third-order moments have physical interpretations of the signs $( \pm)$, giving information about the turbulence bursting events (inward interaction, outward interaction, sweep and ejection events) and are defined as the fluxes of the Reynolds stresses in different directions [39]. Analyses of the third-order moments and turbulent kinetic energy fluxes give valuable information about the near bed turbulence bursting process. Figure 17(a)(d) show the variations of $D u z=\overline{u^{\prime 2} w^{\prime}}$, and $D v r=v^{\prime 3}$ and $D u \theta=u^{\prime 3}$ in the near the bed $(z=0.5 \mathrm{~cm})$ for different sections along the bend in the near bed layer $(z=0.5 \mathrm{~cm})$. In the upstream region of the spur dike $\left(0^{\circ}<\theta<30^{\circ}\right)$ and near the inner bank, parameters $\overline{u^{\prime 3}}$ and $\overline{v^{\prime 3}}$ are positive and $\overline{u^{\prime 2} w^{\prime}}$ is negative. The opposite signs are observed near the outer bank. The crossover points of $\overline{u^{\prime 2} w^{\prime}}$ and $\overline{u^{\prime 3}}$ are approximately at $r=25-30 \mathrm{~cm}$, and the crossover point of $\overline{v^{\prime 3}}$ is at about $r=10 \mathrm{~cm}$. At the upstream nose of the spur dike and reverse flow region, $\overline{u^{\prime 3}}$ and $\overline{u^{\prime 2} w^{\prime}}$ are positive and negative, respectively (Figure 18(b)). This indicates that the high-speed parcels of fluid move towards the bed. Near the upstream nose of the spur dike, the signs of $\overline{u^{\prime 3}}$ and $\overline{u^{\prime 2} w^{\prime}}$ change and their maximum absolute value occurs near the upstream nose of the spur dike. This indicates ejection of the slow moving parcels of fluid into the upper layers of the flow. This also can be observed considering the signs of $\overline{v^{\prime 3}}$ and $\overline{u^{\prime 2} w^{\prime}}$ in Figure 17(a). In the downstream nose of the spur dike, parameters $\overline{u^{\prime 3}}$ and $\overline{u^{\prime 2} w^{\prime}}$ are negative and positive, respectively, with their maximum values at the shear layer region (Figure $17(\mathrm{c})$ ). As a result, the ejection event is more pronounced in the shear layer. As already mentioned, in the high submergence ratio, the upstream reverse flow could not be detected through flow measurement. Figure 17(b) and (d) show the comparison of the high-order moments at the low and high submergence ratios at the upstream nose of the spur dike. At the upstream nose of the highsubmerged spur dike, $\overline{u^{\prime 3}}$ and $\overline{u^{\prime 2} w^{\prime}}$ are negative and positive, respectively, indicating the ejection of the slow moving parcels of fluid to the upper layers of the flow. Parameter $\overline{v^{\prime 3}}$ is positive for $3<r<8 \mathrm{~cm}$ with a peak value at $r=8 \mathrm{~cm}$, indicating the ejection of the fluid parcels to the outer bank. The maximum values of these parameters occur near the nose of the spur dike and between the outer bank and the wing of the spur dike. The maximum values of $\overline{u^{\prime 3}}, \overline{u^{\prime 2} w^{\prime}}$, and $\overline{v^{\prime 3}}$ in the high-submergence ratio are smaller than in the low-submergence ratio, indicating a decrease in the

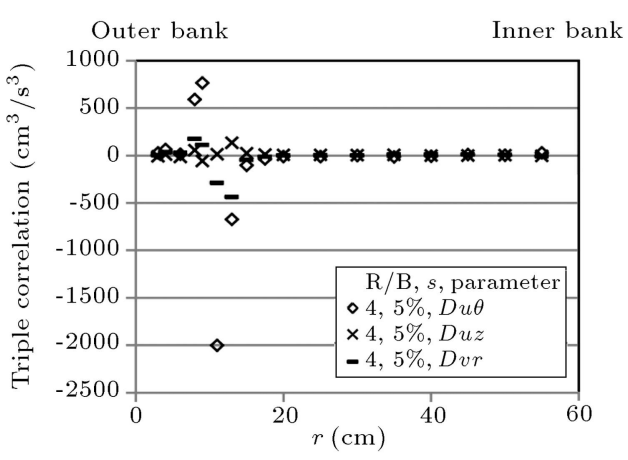

(b)

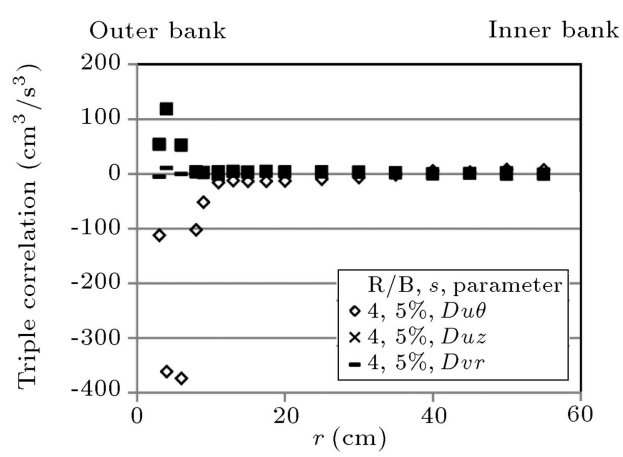

(d)

Figure 17. Variation of the triple correlations in transverse direction: (a) Low submergence at $\theta=30^{\circ}$, (b) low submergence at upstream nose, (c) low submergence at downstream nose, and (d) high submergence at upstream nose of the spur dike. 


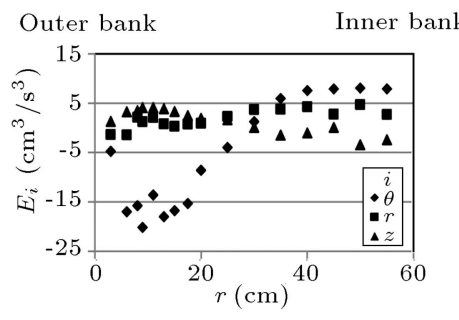

(a)

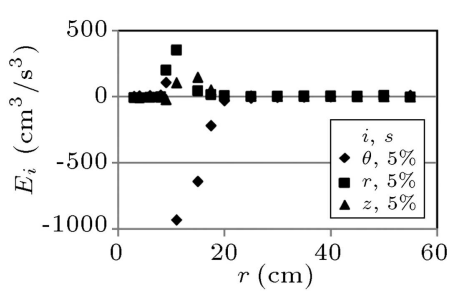

(d)

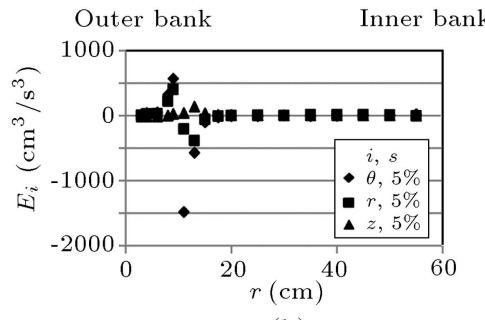

(b)

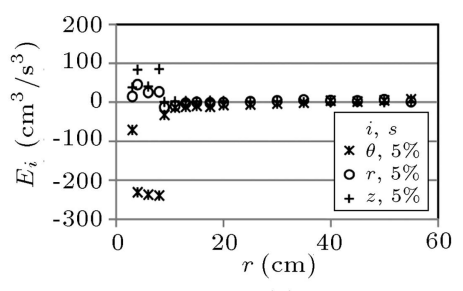

(c)

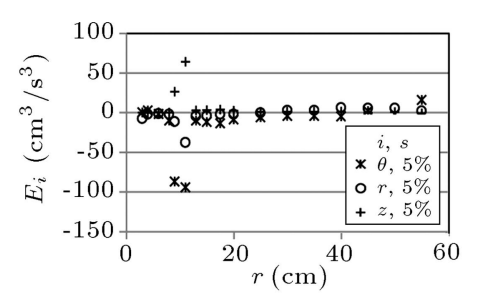

(e)

Figure 18. Variations of the turbulent kinetic energy flux: (a) Low submergence at $\theta=30^{\circ},(\mathrm{b}, \mathrm{c})$ upstream nose, and (d, e) downstream nose of spur dike.

turbulent bursting near the bed layer with an increase in the submergence ratio.

The gradient of the turbulent kinetic energy flux shows the rate of the gain or loss due to diffusion. The turbulent kinetic energy fluxes in tangential direction, $E_{\theta}$, radial direction, $E_{r}$, and vertical direction, $E_{z}$ were calculated using Eqs. (15)-(17) [23]:

$$
\begin{aligned}
& E_{\theta}=0.5\left(\overline{u^{\prime 3}}+\overline{u^{\prime} v^{\prime 2}}+\overline{u^{\prime} w^{\prime 2}}\right), \\
& E_{r}=0.5\left(\overline{v^{\prime} u^{\prime 2}}+\overline{v^{\prime 3}}+\overline{v^{\prime} w^{\prime 2}}\right), \\
& E_{z}=0.5\left(\overline{w^{\prime} u^{\prime 2}}+\overline{w^{\prime} v^{\prime 2}}+\overline{w^{\prime 3}}\right) .
\end{aligned}
$$

Figure 18(a)-(e) show the variation of the turbulent kinetic energy flux in the near-bed layer $(z=0.5 \mathrm{~cm})$ for each direction of the low and high submergence ratios. At $\theta=30^{\circ}$ and $3<r<30 \mathrm{~cm}$, the turbulent kinetic energy is positive in the vertical direction and negative in the tangential direction (Figure 18(a)). This indicates the displacement of the turbulent kinetic energy toward the water surface and to the upstream. By increasing the distance from the outer bank, the signs of the turbulent kinetic energy fluxes change in the vertical and tangential directions.

Figure 18(b) and (c) show the variations of the turbulent kinetic energy fluxes in the lateral direction. At the upstream nose of the low-submerged spur dike, for $3<r<8 \mathrm{~cm}$, the turbulent kinetic energy fluxes in the tangential and radial directions are positive, while the turbulent kinetic energy flux in the vertical direction is negative, with the peak values near the upstream nose of the spur dike. In the range of $11<r<55 \mathrm{~cm}$, the signs of $E_{\theta}, E_{r}$, and $E_{z}$ change. The peak values of these parameters occur at $r=11$ and $13 \mathrm{~cm}$. In the high-submergence ratio, the turbulent kinetic energy flux is negative in the tangential direction and positive in the radial and vertical directions. At the high-submergence ratio, the peak value of the turbulent kinetic energy flux occurs at $r=8 \mathrm{~cm}$. The peak values of the turbulent kinetic energy fluxes in the low-submergence ratio are greater than those in the high submergence ratio.

At the downstream nose section of the spur dike (Figure 18(d) and (e)), the turbulent kinetic energy fluxes are greater in the shear layer region in comparison with those in the other regions. When $3<r<9$ $\mathrm{cm}$, parameters $E_{\theta}$ and $E_{r}$ are positive, while $E_{z}$ is negative. The signs of $E_{\theta}$ and $E_{z}$ change at $r=11 \mathrm{~cm}$ and the peak values of $E_{\theta}$ and $E_{z}$ occur at $r=11 \mathrm{~cm}$. Again, the peak values of the turbulent kinetic energy fluxes in the low-submergence ratio are greater than those in the high-submergence ratio.

\section{Discussion on and implications of scour and sediment transport}

In the first stage of this section, the results of the sour experiments are presented and the relations between the scour process and flow field will be presented in the following stages. According to the observations, the scour started from the upstream nose (zone 1 in Figure 19) of the spur dike and elongated along the border of the spur dike and approaching flow (shear layer region, zone 2 of Figure 19). Sediment was transported as a suspended load in the early stages of the scour process. This process later switched to the bed load transport. Two main differences were observed in the early-stage scour process of the sediment transport around the two spur dikes (zone 3 of Figure 19). One is the scour due to the falling flow in the downstream 


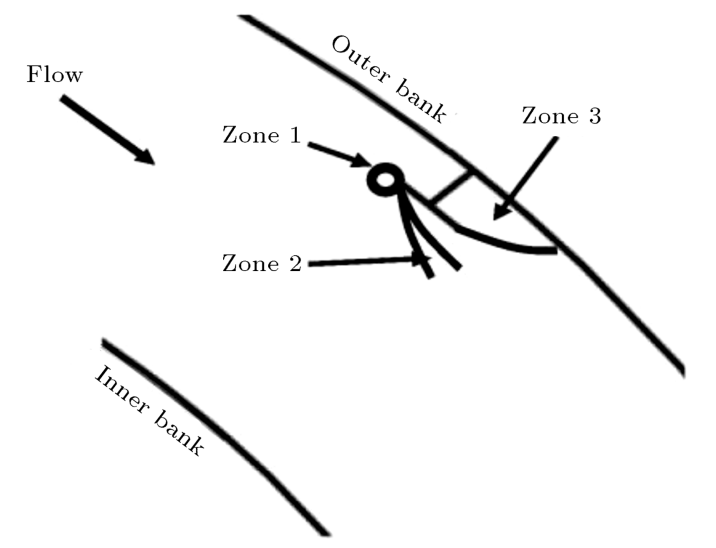

Figure 19. Schematic view of the different scour zone.

recirculation flow of the high-submergence spur dike. Two is the sediment deposition rate and mechanisms in the downstream recirculation zone of the spur dikes. In the high submergence condition, the free falling flow from the crest of the spur dike is strong. The sediment was transported to the upstream and deposited in the region between the spur dike wing and the outer bank. This process was not observed for the low-submerged spur dike. In the low-submerged spur dike, the sediment that moved to the downstream was deposited in the recirculation region due to the sucking effect of the downstream recirculation flow. The deposition process in the recirculation region of the high-submergence condition was more pronounced as compared to that of the low-submergence condition, and the sediment level in the downstream recirculation region of the high-submergence spur dike reached the crest of the spur dike 30 minutes away from the scour initiation. Figure 20 shows the variation rate of the maximum scour depth for the low- and high-submergence spur dikes. As one can see, at the same point in time, the scour rate in the low-submergence spur dike is more than that in the high submergence spur dike. Khosravi [40] and Shariatzadeh [41] also reported that the maximum scour depth in the asymptotic state in

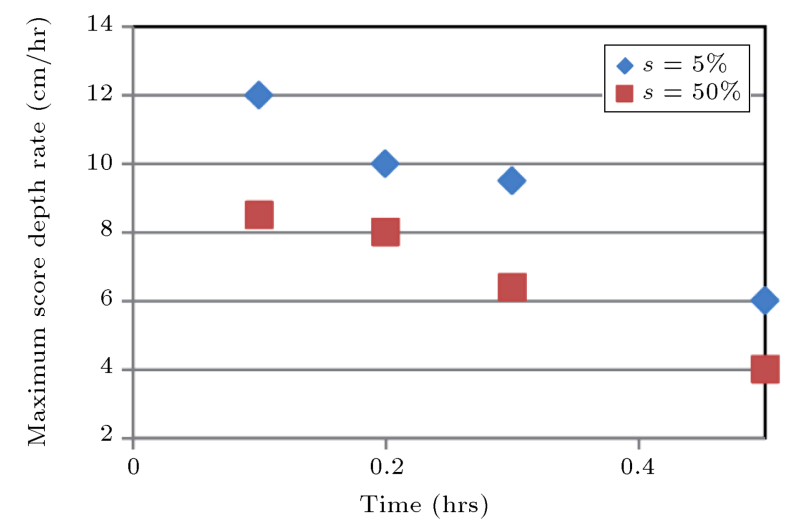

Figure 20. Maximum scour depth rate variation with time. the low-submergence condition is more than that in the high-submergence condition. For low and high submergence conditions, the maximum scour depths occurred near the upstream nose of the spur dikes.

According to the mean flow analysis, spur dike nose flow is more pronounced in the low-submerged condition, but spur dike overflow is prevailing in the high-submerged condition. Strong spur dike nose flow may be one of the reasons behind the scour rate increment as the submergence decreases. However, strong spur dike overflow is the main reason for scour hole formation in the downstream region of the highsubmerged spur dike. The maximum shear stress (using Reynolds shear stresses) occurred near the upstream nose of the spur dikes, and the maximum value in the low-submerged spur dike was greater than that in the high-submerged spur dike. This confirms that the flow field around the low-submerged spur dike is more given to scour and sediment transport. As the scour for the two spur dikes started from the upstream nose of the spur dike, the bed shear stress estimation using the Reynolds stresses is a good indicator of the scour initiation regions. The results are in accordance with those of Dey and Barbhuiya [6] and in contradiction to those of Yaeger (2009) [21]. In the upstream nose section, the maximum vertical velocity variance occurred near the outer bank; hence, the bed shear stress estimation using linear relationship with vertical velocity variance cannot predict the scour initiation region correctly. According to the spectral analysis, the peak value of the power spectrum for the points around the low-submerged spur dike shows the greater ability of the vortices in sediment movement compared to the peak value around the high-submergence spur dike. The sweep and ejection events have more contributions in Reynolds stresses for the points near the spur dike and in the shear layer region. In addition, these events are more repetitive near the spur dike wing. Hence, not surprisingly, the scour starts from the spur dike wing nearly and elongates in the shear layer region. The interaction events have negative signs in the Reynolds stresses, hence more contribution and time fraction of these events in the downstream recirculation region lead to sediment deposition. The shorter period of the ejection and sweep events around the low-submerged spur dike is another reason for an increase in the scour potential of the flow around this type of spur dikes when compared to the high-submerged spur dike. The triple correlations and the turbulent kinetic energy flux showed that the sweep and ejection events are the predominant events near the upstream nose of the spur dike, and the events in the low-submerged spur dike condition are stronger than those in the high-submerged conditions. This also confirms that spur dike nose flow of the low-submerged spur dike transported more sediment from the upstream nose of 
the low-submerged spur dike, and this is in accordance with the scour depth. The deposition process of the sediment can be expected in the downstream recirculation region as the triple correlations and the turbulent kinetic energy flux showed that the interaction events have the main role in near-bed turbulent flow field in this region.

\section{Conclusions}

In this paper, the flow field and scour around the submerged spur dike were experimentally investigated, and the effect of submergence ration on flow field and scour was clarified. The results showed that the passing flow around the low-submerged spur dike is larger than the passing flow around the high-submerged spur dike, but that the overflow from the high-submerged spur dike crest is larger than that from the low-submerged spur dike. This difference plays the main role in the scour process and flow fields around the spur dikes. The scour process started from the upstream nose of the spur dike and elongated along the shear layer region, and the scour rate in the low-submerged spur dike was more than that in the high-submerged spur dike. A deposition process occurred in the downstream recirculation region of the spur dike and was more pronounced in the high-submerged spur dike. The scour and flow field relations were analyzed as well. Results showed that the scour initiation region can be predicted through the shear stress estimation using Reynolds stresses, but there is no relationship between the vertical velocity variance and scour process. The triple correlation and turbulent kinetic energy flux are strongly related to the scour process. These parameters can, in addition, predict the variation trend of the maximum scour hole depth with a submergence ratio. The power spectrum analysis along with the period of the events analysis showed that the strong vortices with high recurrence of the sweep and ejection events in the near spur dikes are some other effective parameters on scour process, increasing the maximum scour depth ratio by decreasing the submergence of the spur dike. The interaction events are prevailing events in the recirculation region and have the main role in sediment deposition. Although the scour process was related to some turbulent parameters in this paper, it is recommended to check the availability of the results for other complex 3D flow fields.

\section{Nomenclature}

$\begin{array}{ll}C & \text { Constant } \\ d_{50} & \text { The median sediment size } \\ E_{r} & \text { Turbulent kinetic energy flux in radial } \\ & \text { direction }\end{array}$

\begin{tabular}{|c|c|}
\hline$E_{z}$ & $\begin{array}{l}\text { Turbulent kinetic energy flux in } \\
\text { vertical direction }\end{array}$ \\
\hline$E_{\theta}$ & $\begin{array}{l}\text { Turbulent kinetic energy flux in } \\
\text { tangential direction }\end{array}$ \\
\hline$f$ & Frequency of velocity measurement \\
\hline$D u z=\overline{u^{\prime 2} w^{\prime}}$ & \\
\hline$D u r=\overline{v^{\prime 3}}$ & Triple correlations \\
\hline$D u \theta=\overline{u^{\prime 3}}$ & \\
\hline$h$ & Hole size \\
\hline$H$ & Water depth \\
\hline$I_{i}(t)$ & Detection function \\
\hline$\rho_{q}(\varphi)$ & Probability density function \\
\hline$K$ & Maximum lag or truncation time \\
\hline$K_{0}(|x|)$ & $\begin{array}{l}\text { 0th order modified Bessel function of } \\
\text { second kind }\end{array}$ \\
\hline$L$ & Spur dike web length \\
\hline$L$ & Spur dike wing length \\
\hline$N$ & Total data number \\
\hline$r$ & Distance from outer bank \\
\hline$R$ & $\begin{array}{l}\text { Correlation coefficient of the Reynolds } \\
\text { stress }\end{array}$ \\
\hline$R_{S}(H)$ & $\begin{array}{l}\text { Contribution rate of the events in } \\
\text { Reynolds stresses }\end{array}$ \\
\hline$S(f)$ & Power spectrum \\
\hline$s_{j}(f)$ & Energy spectrum in $j$ direction \\
\hline$T_{s}(H)$ & Time fraction \\
\hline$U$ & Mean approach flow velocity \\
\hline$u_{j}^{\prime}$ & $\begin{array}{l}\text { Surface component velocity fluctuation } \\
\left(u^{\prime}, v^{\prime}\right)\end{array}$ \\
\hline$w^{\prime}$ & Depth velocity fluctuation component \\
\hline$Y$ & Spur dike height \\
\hline$\Delta t$ & Time lag \\
\hline$\tau r$ & $\begin{array}{l}\text { Bed shear stress estimation in radial } \\
\text { direction }\end{array}$ \\
\hline$\tau R e$ & $\begin{array}{l}\text { Bed shear stress estimation using } \\
\text { Reynolds stress }\end{array}$ \\
\hline$\tau w^{\prime}$ & $\begin{array}{l}\text { Bed shear stress estimation using } \\
\text { vertical velocity fluctuation }\end{array}$ \\
\hline$\tau \theta$ & $\begin{array}{l}\text { Bed shear stress estimation in } \\
\text { tangential direction }\end{array}$ \\
\hline$\varphi$ & $\begin{array}{l}\text { Non-dimensional form of the } \\
\text { instantaneous Reynolds stress }\end{array}$ \\
\hline$\theta$ & Location of the spur dike in the bend \\
\hline
\end{tabular}

\section{References}

1. Chen, F.Y. and Ikeda, S. "Horizontal separation flows in shallow open channels with spur dikes", J. Hydro. Sci. Hydraul. Eng., 15(2), pp. 15-30 (1997). 
2. Elawady, E., Michiue, M. and Hinokidani, O. "Experimental study of flow behavior around submerged spurdike on rigid bed", Ann. J. Hydraul. Eng., 44, pp. 539544 (2000).

3. Elawady, E., Michiue, M. and Hinokidani, O. "Movable bed scour around submerged spur-dikes", Ann. J. Hydraul. Eng., 45, pp. 373-378 (2001).

4. Yossef, M.F.M. "The effects of groynes on rivers (literature review)", Delft Cluster Report No. DC1334-4, Delft University, The Netherlands (2002).

5. Dey, S. and Lambert, M.F. "Reynolds stress and bed shear in non-uniform unsteady open-channel flow", $J$. Hydraul. Eng-ASCE, 131(7), pp. 610-614 (2005).

6. Dey, S. and Barbhuiya, A.K. "Velocity and turbulent in a scour hole at a vertical-wall abutment", Flow. Meas. Instrum., 17(1), pp. 13-21 (2006).

7. Duan, J.G., He, L., Wang, G.Q. and Fu, X.D. "Mean flow and turbulence around experimental spur dike", Adv. Water. Resour., 32(12), pp. 1717-1725 (2009).

8. Vaghefi, M., Ghodsian, M. and Salehi Neyshaboori, S.A.A. "Experimental study on the effect of a Tshaped spur dike length on scour in a $90^{\circ}$ channel bend", Arab. J. Sci. Eng., 34(2), pp. 337-348 (2009).

9. Azinfar, H. "Flow resistance and associated backwater effect due to spur dikes in open channels", PhD Thesis, University of Saskatchewan, Saskatoon (2010).

10. Duan, J.G., He, L., Wang, G.Q. and Fu, X.D. "Turbulent burst around experimental spur dike", Int. J. Sediment. Res., 26(4), pp. 471-486 (2011).

11. Kuhnle, R.A., Jia, Y. and Alonso, C.V. "Measured and simulated flow near a submerged spur dike", $J$. Hydraul. Eng-ASCE, 134(7), pp. 916-924 (2008).

12. Ghodsian, M. and Vaghefi, M . "Experimental study on scour and flow field in a scour hole around a $\mathrm{T}$ shaped spur dike in a $90^{\circ}$ bend", Int. J. Sediment. Res., 24(2), pp. 145-158 (2009).

13. Safarzadeh, A., Salehi, S.A.A., Ghodsian, M. and Zarrati, A.R. "Experimental study of head shape effects on shear stress distribution around a single groyne", The Proceeding of River Flow, 1, pp. 651-658 (2010).

14. Grass, A.J. "Structural features of turbulent flow over smooth and rough boundaries", J. Fluid. Mech., 50(2), pp. 233-255 (1971).

15. Nezu, I. and Nakagawa, H. "Turbulent in open-channel flow", Balkema, Rotterdam, The Netherlands (1993).

16. Nakagawa, H. and Nezu, I. "Predictions of the contributions to the Reynolds stress from bursting events in open-channel flows", J. Fluid. Mech., 80(1), pp. 99-128 (1997).

17. Nelson, J.M., Shreve, R.L., Mclean, S.R. and Drake, T.G. "Role of near-bed turbulence structure in bed load transport and bed form mechanics", Water. Resour. Res., 31(8), pp. 2071-2086 (1995).
18. Keshavarzy, A.R. and Ball, J.E. "An analysis of the characteristics of rough bed turbulent shear stresses in an open channel", Stoch. Env. Res. Risk. A., 11, pp. 193-210 (1997).

19. Keshavarzy, A.R. and Gheisi, A.R. "Stochastic nature of three dimensional bursting events and sediment entrainment in vortex chamber", Stoch. Env. Res. Risk. A., 21(1), pp. 75-87 (2006).

20. Bey, A., Faruque, M.D. and Balachandar, R. "TwoDimensional scour hole problem: role of fluid structures", J. Hydraul. Eng-ASCE., 133(4), pp. 414-431 (2007).

21. Yaeger, M.A. "Mean flow and turbulence around two series of experimental dikes", MSc thesis, University of Arizona, Arizona (2009).

22. Yager, E.M and Schmeeckle, M.W. "The influence of vegetation on turbulence and bed load transport", $J$. Geophys. Res-Earth, 118, pp. 1585-1601 (2013).

23. Mehraein, M., Najibi, S.A. and Ghodsian, M. "Experimental investigation on the flowfield around a spur dike in a $90^{\circ}$ sharp bend", Int. Sym. on Ultrasonic Doppler Meth. Fluid Mech. Fluid Eng., pp. 173-176 (2014a).

24. Mehraein, M., Ghodsian, M. and Najibi, S.A. "Location effect on near bed flow structure around a straight spur dike", River Flow., pp. 743-749 (2014b).

25. Mehraein, M., Noorbakhsh, S.A. and Ghodsian, M. "Experimental study of flow pattern around a submerged spur dike", Modares. Civil. Eng. J., 15(3), pp. 171-178 (2015). (In Persian)

26. Sarkar, S. "Turbulence in loose boundary streams", $\mathrm{PhD}$ Thesis, Department of Civil Engineering, Indian institute of technology, Kharagpur, India (2010).

27. Soltani Gerdfaramarzi, S., Afzalimehr, H. and Fazel Najafabadi, E. "Application of quadrant analysis in determination of bursting values in scouring around bridge pier", J. Hydraul, IHA, 15(1), pp. 65-75 (2015). (In Persian)

28. Shrestha, C.K. "Bridge pier flow interaction and its effect on the process of scouring", PhD Thesis, University of Technology Sydney, Sydney (2015).

29. Marchioli, C. and Soldati, A. "Mechanisms for particle transfer and segregation in a turbulent boundary layer", J. Fluid. Mech., 468, pp. 283-315 (2002).

30. Mianaei, S. and Keshavarzy, A.R. "Spatio-temporal variation of transition probability of bursting events over ripples at the bed of the open channel", Stoch. Env. Res. Risk. A., 22(2), pp. 257-264 (2008).

31. Leschziner, M.A. and Rodi, W. "Calculation of strongly curved open channel flow", J. Hydraul. Div$A S C E, \mathbf{1 0 5}(10)$, pp. 1297-1314 (1979).

32. Nortek "Vectrino velocimeter user guide", Vangkroken, Norway (2004).

33. Goring, D. and Nikora, V. "Despiking acoustic Doppler velocimeter data", J. Hydraul. Eng-ASCE, 128(1), pp. 117-126 (2002). 
34. Jenkins, G.M. and Watts, D.G. "Spectral analysis and its applications", Holden Day, San Francisco (1968)

35. Annandale, G., Scour Technology, McGraw-Hill (2005).

36. Roussinova, V. "Turbulent structures in smooth and rough open channel flows: effect of depth", $\mathrm{PhD}$ Thesis, University of Saskatchewan, Saskatoon (2009).

37. Biron, P.M., Robson, C., Lapointe, M.F. and Gaskin, S.J. "Comparing different methods of bed shear stress estimates in simple and complex flow fields", Earth. Surf. Proc. Land., 29(11), pp. 1403-1415 (2004).

38. Kim, S.-C., Friedrichs, C.T., Maa, J.P.-Y. and Wright, L.D. "Estimating bottom stress in tidal boundary layer from acoustic Doppler velocimeter data", J. Hydraul. Eng-ASCE., 126(6), pp. 399-406 (2000)

39. Dey, S., Fluvial Hydrodynamics, Springer (2014).

40. Khosravi Mashizi, M. “ Experimental study of scour and flowfield around a submerged $\mathrm{T}$ shaped spur dike in a $90^{\circ}$ bend", MSc Thesis, Faculty of Civil and Environmental Engineering, Tarbiat Modares University, Tehran (2010).

41. Shariatzadeh, Y. "Experimental study on scour and flowfield around an attracted and repelling spur dike in a $90^{\circ}$ bend", MSc Thesis, Faculty of Civil and Environmental Engineering, Tarbiat Modares University, Tehran (2010).

\section{Biographies}

Mojtaba Mehraein received PhD degree from Tarbiat Modares University in 2011. His research interests include experimental and numerical investigation of scour and flow field around the hydraulic structures. Now, he is an Assistant Professor at Kharazmi University of Tehran.

Masoud Ghodsian obtained his $\mathrm{PhD}$ in 1992 from Indian Institute of Technology-Roorkee, India. He started his academic and research activities when he joined Tarbiat Modares University, Tehran, in 1992. He has published about 80 peer reviewed journal papers and about 160 papers in the international and national conferences. His field of research activities includes river engineering, hydraulic structure, and scouring and sediment transport. 